\title{
Hair resistance to mechanical wear
}

\author{
Artur Ribeiro $^{1}$, Madalena Martins ${ }^{1}$, Ana Tinoco, Artur Cavaco-Paulo \\ Centre of Biological Engineering, University of Minho, Campus de Gualtar, 4710-057, Braga, Portugal
}

\section{A R T I C L E I N F O}

\section{Keywords:}

Mechanical wear

Friction

Hair

Cosmetic treatment

\begin{abstract}
A B S T R A C T
Hair mechanical properties are primary indicators of hair integrity. Here we describe a methodology based on hair's resistance to mechanical wear to evaluate cosmetic treatments. Using a vibrational vortex cycle, we developed a protocol that relies on the plastic deformation and degradation of hair, due to frictional forces between hardened steel balls and hair fragments. We demonstrate that the balls when in contact with the hair fragments promoted extended hair degradation. The degree of degradation was related to hair's resistance to mechanical wear. Lower degradation rates reflect high resistance to mechanical wear. We found differences according to hair ethnicity and type of treatment. This methodology shows great potential for the screening and evaluation of the effect of cosmetic treatments on hair.
\end{abstract}

\section{Introduction}

Hair appearance has been widely explored throughout history, remaining very important in modern society [1]. The development of new hair cosmetic treatments to change and/or control hair features like colour, shape, volume, strength, gloss and touch, is of great importance for hair cosmetic industry [2-6]. These products can be formulated to respond to personal preferences and to the needs of different types of hairs and hair ethnicities [7-10]. However, the repeated use of cosmetic products and chemical procedures including chemical dyes, bleaches, permanent wave and straightening treatments, could damage the hair fibers and affect the hair structure and hair properties [1,5,11]. Thus, the evaluation of a formulation effect is an essential step during the development of new hair cosmetic products.

Hair mechanical properties like resistance and elongation at break are currently used as primary indicators of hair integrity and give information regarding the effect of a formulation/compound over the hair fibre. However, the methodologies used to measure hair's mechanical properties are usually time-consuming, demand multiple measurements (at least thirty single hair should be tested for each condition) and are prone to variation $[3,6,12,13]$.

Mechanical resistance of the hair can be evaluated by suitable equipment intended for measuring the strength or elasticity properties of the hair fibres. For example, these features can be measured using a dynamometer. The device exerts a tension force or load on the single fibre fixed on a support, disrupting the fibre, which is recorded by the software, converting the information into load graphic of elongation [14-16]. The measurement of breaking force is required to quantify the hair fibres strength. The rupture load of a hair thread is directly proportional to the thread length. The use of conventional tensile testing experiments has been described to generate stress-strain curves to characterize the structural integrity of individual hair fibres. While this method provides a general characterization, some questions remain, concerning the relevance and the reproducibility of experimental results to real-life occurrences [17]. Moreover, the differences in hair's physical properties and shape, related to hair ethnicity, give differential mechanical properties to the hair fibres [18]. Due to the variation and the complex biological diversity of hair, it is important to establish how each type of hair fibre responds in terms of mechanical resistance.

Here we investigated the implementation of a new methodology to study the effect of cosmetic treatments on the protection and recovery of hair properties, evaluated in terms of increase in the hair resistance to wear. Mechanical wear experiments, based on compression and frictional forces between hair fragments and hardened steel balls during a vibrational vortex cycle, were performed demonstrating the loss mass variation in a predictable manner according to hair's ethnic background and type of hair treatment (Fig. 1). The hardened steel balls, when in contact with the hair fragments during vortex, will compromise the integrity of the hair fibres. In this process, the hair fragments are plastically deformed and degraded due to frictional forces between the balls

\footnotetext{
Abbreviations: KP, keratin-based peptide; Cryst, $\gamma \mathrm{D}$-crystallin; SEM, Scanning Electron Microscopy.

* Corresponding author

E-mail address: artur@deb.uminho.pt (A. Cavaco-Paulo).

1 The authors have equally contributed.
} 
and the hair fragments, promoting the formation of hair particles with differentiated sizes. The size of the hair particles at the end of the mechanical insult will depend on the initial integrity of the hair to be tested.

Using a membrane with $5 \mu \mathrm{m}$ pore size, the hair particles are separated according to their size. Particles smaller than $5 \mu \mathrm{m}$ are discarded and considered as the hair mass lost due to the mechanical wear test, while the bigger particles constitute the remaining hair material. It is expected that hair fibres with lower initial integrity present higher mass losses and lower resistance to mechanical wear when compared with the fibres with higher initial integrity. By these experiments, virgin hair and chemically treated hair were compared according to their ethnic origin, giving valuable information regarding how hair's ethnicity influence the behaviour of the hair in terms of resistance to wear.

A protein-based cosmetic formulation, known to protect hair from thermal damage, was used to validate the mechanical wear methodology [19]. The formulations containing the KP-Cryst fusion proteins were applied onto hair and its effect on hair properties was evaluated in terms of increase of the resistance to mechanical wear (mass loss) and improvement of hair mechanical properties (Young's Modulus). The KP-Cryst Wt and KP-Cryst Mut proteins are based on the sequences of human eye $\gamma \mathrm{D}$-crystallin (Cryst) and a keratin-based peptide (KP) $[3,13]$. These fusion proteins combine the thermodynamic stability of $\gamma \mathrm{D}$-crystallin with the ability of the KP peptide to bind to the hair. In order to improve the stability of the proteins and their capacity to bind to the hair, a mutant crystallin was designed by the substitution of three arginine residues by three cysteines, on the wild-type crystallin sequence $[13,20]$.

The mechanical wear methodology, here described for the first time, was designed in order to be used for the screening of hair cosmetic treatments avoiding time-consuming techniques and the use of a great number of hair samples. Initially, an optimization of the methodology was performed in terms of hair fragments size and time of mechanical insult. The results were expressed in terms of resistance to wear and Young's Modulus, and the hair samples were analysed by scanning electron microscopy.

\section{Materials and methods}

Caucasian brown, Caucasian blonde and Asian virgin hairs were provided by International Hair Importers \& Products Inc. (Glendale, New York U.S.A.). African virgin hair was donated by a local hairdressing salon. Non-corrodible hardened steel balls (50WW-0015/B/S/ A) with a diameter of $6001 \pm 0,002 \mathrm{~mm}$ and a weight of 900,6 $\pm 0,508$ $\mathrm{mg}$, were purchased from Roaches International (Birstall, West Yorkshire, England). Isopore membrane filters ( $5.0 \mu \mathrm{m}$ pore size, hydrophilic polycarbonate membrane, $47 \mathrm{~mm}$ diameter) were obtained from MerckSigma, Spain. The kit used for the colour treatment (permanent colour, acajou Casting Creme Gloss L'Oreal) was commercially available and used following manufacturer instructions. The kits for overbleaching (Lightning powder with oxidizing cream $12 \% 40$ vol, Revlon) and for the permanent chemical straightening or waving (oxidizing and neutralizing product, Real Natura Cosmetics) were commercially available and used according to manufacturer instructions. All the other reagents were used as received.

\subsection{Mechanical wear test optimization}

An optimization of the methodology was performed regarding the size of the hair fragments and the time of duration of the mechanical wear test. For that, $10 \mathrm{mg}$ of Caucasian brown hair fragments (virgin and overbleached) with $0.25,0.5$, and $1 \mathrm{~cm}$ of length were incubated with 5 hardened steel balls (diameter $6001 \pm 0,002 \mathrm{~mm}$, weight 900,6 \pm 0,508 $\mathrm{mg}$ ) and $700 \mu \mathrm{l}$ of water in Eppendorf tubes with $2 \mathrm{ml}$ capacity. The friction between the hair samples and the hardened steel balls was promoted by a vortex cycle at $2500 \mathrm{rpm}$ for $3 \mathrm{~h}$. This vortex parameters guaranteed differentiated hair degradation profiles according to the type of hair (vigin vs overbleached) and to the size of the hair fragments (Fig. 2). The reaction mixture was then filtered using polycarbonate membrane filters with $5.0 \mu \mathrm{m}$ pore size. The membranes with a $5 \mu \mathrm{m}$ pore size were considered adequate to observe differences in the resistance to mechanical wear between hair samples with differentiated integrity profiles. It is expected that a treatment which is damaging to the hair will compromise the properties of the fibres, leading to the formation of a higher number of hair particles with sizes bellow $5.0 \mu \mathrm{m}$ (hair mass loss), when compared with a less damaging treatment.

To guarantee that no hair material was lost, all the samples and Eppendorf tubes were washed 5 times with $700 \mu$ l of water before balls

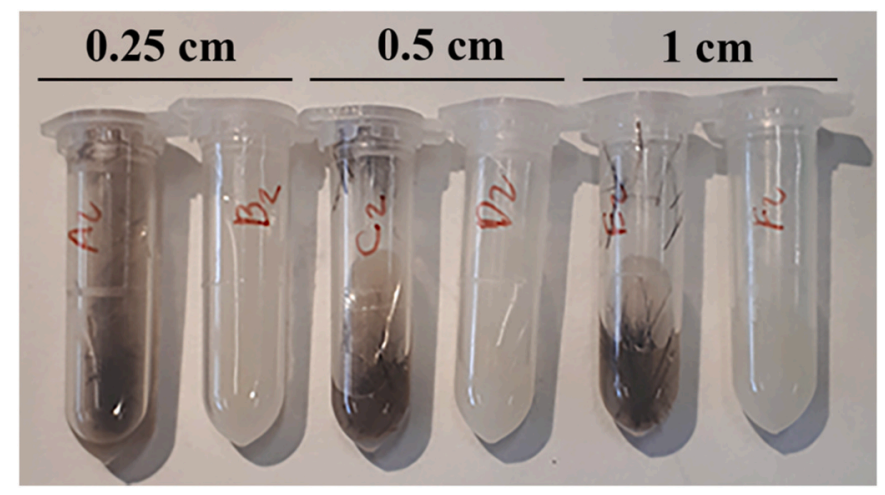

Fig. 2. Visual inspection of the fragments of virgin and overbleached Caucasian hair, with $0.25,0.5$ and $1 \mathrm{~cm}$ of length, after $3 \mathrm{~h}$ of mechanical wear test.

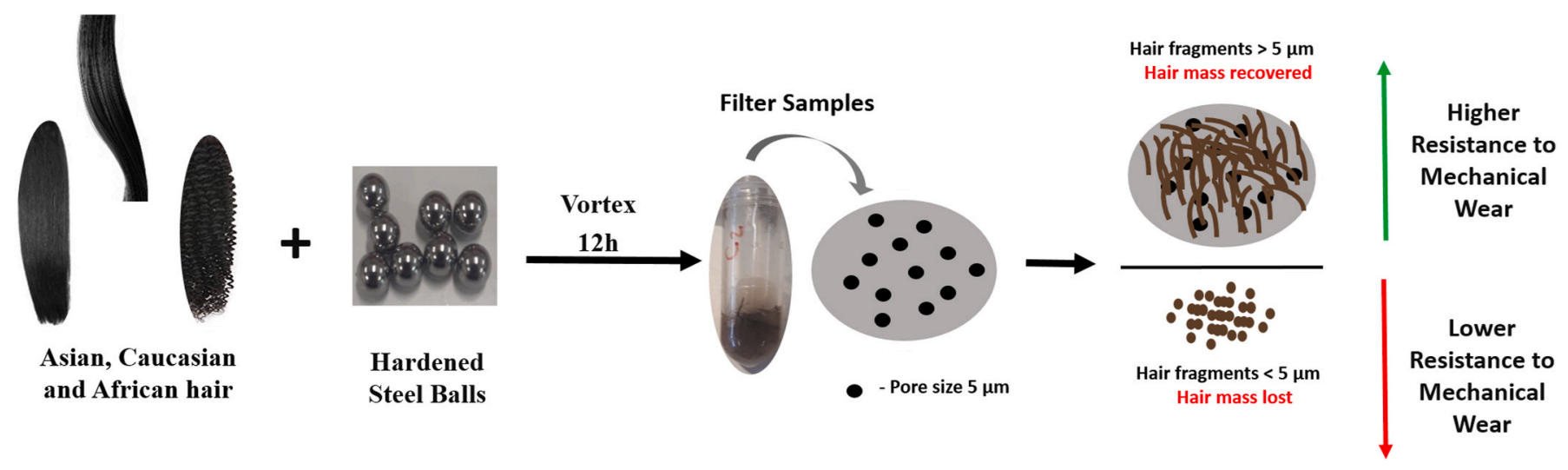

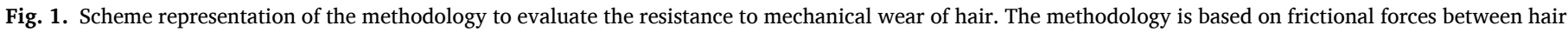
fragments and hardened steel balls during a vibrational vortex cycle. 
removal. The filters with the hair material (fragments and particles with sizes bigger than $5.0 \mu \mathrm{m}$ ) were dried at $40{ }^{\circ} \mathrm{C}$ for $24 \mathrm{~h}$ and the samples were weighed. The amount of hair mass loss was determined by equation (1):

Hair mass $\operatorname{loss}(\%)=\left(\frac{H i-H f}{H i}\right) * 100$

where $\mathrm{H}_{\mathrm{i}}$ corresponds to the initial amount of hair and $\mathrm{H}_{\mathrm{f}}$ to the final amount of hair present in the polycarbonate membrane filter.

The resistance to wear expressed in percentage was calculated according to equation (2):

Resistance to wear $(\%)=100 \%$ - Hair mass loss $(\%)$

Based on the results obtained for the hair fragments size, only the fragments with 0.5 and $1 \mathrm{~cm}$ were considered for the optimization of the friction time between the hair samples and the hardened steel balls. The experiments were performed as previously described, with the hair samples being subjected to $1,3,6,12$ and $24 \mathrm{~h}$ of vortex ( $2500 \mathrm{rpm}$ ) with the hardened steel balls. The resistance to wear was calculated according to equations (1) and (2).

\subsection{Effect of hair ethnicity and treatment on hair's mass loss}

To study the effect of hair ethnicity (Caucasian, African and Asian) and the effect of different hair cosmetic treatments (no treatment, overbleaching, coloration and straightening/waving) on the amount of mass loss after mechanical wear caused by frictional forces between the hair fragments and the hardened steel balls, $10 \mathrm{mg}$ of hair fragments with $0.5 \mathrm{~cm}$ of length, 5 hardned steel balls and $700 \mu \mathrm{l}$ of water were vortexed inside an $2 \mathrm{ml}$ Eppendorf tube at $2500 \mathrm{rpm}$ for $12 \mathrm{~h}$. The mixture was then filtered using polycarbonate membrane filters with $5.0 \mu \mathrm{m}$ pore size, and the filters with the hair material (fragments and particles with sizes bigger than $5.0 \mu \mathrm{m}$ ) were dried at $40{ }^{\circ} \mathrm{C}$ for $24 \mathrm{~h}$ and the samples were weighed. The hair mass loss and resistance to wear were determined following equations (1) and (2).

\subsection{Scanning electron microscopy (SEM) analysis}

The analyses of the hair samples after the mechanical wear test were performed using a desktop Scanning Electron Microscope (Phenom ProX, Netherlands), with the ProSuite software. The hair samples present in the polycarbonate membrane filters were placed on aluminium pin stubs covered with electrically conductive carbon adhesive tape (PELCO Tabs ${ }^{\mathrm{TM}}$ ). Before analysis, the samples were covered with $20 \AA$ of gold to improve samples' electrical conductivity.

\subsection{Hair treatment with a protein-based cosmetic formulation}

Two fusion proteins, KP-Cryst Wt and KP-Cryst Mut were applied to Caucasian virgin brown hair and the treated hairs were used to validate the mechanical wear test by comparison with the fibre tensile test. The hair strands were washed with a classic commercial shampoo (Pantene ${ }^{\circledR}$ Pro-V Classic), before treatment. For the treatments, $100 \mathrm{mg}$ of Caucasian virgin brown hair was incubated with the KP-Cryst Wt or with the KP-Cryst Mut fusion proteins, dissolved in a buffer composed by $25 \mathrm{mM}$ HEPES and $120 \mathrm{mM} \mathrm{NaCl}$, at pH5 and pH9. Prior treatment, the hair strands were pre-conditioned with $250 \mu \mathrm{L}$ of the buffer, for $15 \mathrm{~min}$ at room temperature, and then dried with the hairdryer. Then, $250 \mu \mathrm{L}$ of protein solution $(1 \mathrm{mg} / \mathrm{mL})$ was applied to the hair strands, incubated for $15 \mathrm{~min}$, and dried with the hairdryer. This step was repeated 5 times. All samples were thoroughly washed in tap water with the commercial shampoo and dried with hairdryer $24 \mathrm{~h}$ after treatment.

The treated and untreated hair samples were evaluated regarding their resistance to mechanical wear and their mechanical properties.

\subsubsection{Mechanical wear test}

The effect of the treatment with the KP-Cryst fusion proteins on the resistance to the mechanical wear expressed as a reduction or as an increase on hair's mass loss was evaluated as described in sections 2.1. and 2.2. Shortly, $10 \mathrm{mg}$ of hair fragments with $0.5 \mathrm{~cm}$ of length were vortexed at $2500 \mathrm{rpm}$ for $12 \mathrm{~h}$, with 5 hardened steel balls and $700 \mu \mathrm{l}$ of water, in an Eppendorf tube with $2 \mathrm{ml}$ capacity. The samples were filtered using polycarbonate membrane filters with $5 \mu \mathrm{m}$ pore size and the resistance to wear was determined using equations (1) and (2), after samples drying at $40{ }^{\circ} \mathrm{C}$ for $24 \mathrm{~h}$.

\subsubsection{Hair fibre tensile test}

Hair fibres' mechanical properties (Young's modulus) were assessed using a dynamometer Hounsfield machine, in order to study the effect of the treatment with the KP-Cryst fusion proteins on hair. The differences in hairs' mechanical properties were determined following the guidelines outlined in ASTM D1145-95 for fibre tensile testing. For these, 30 single hair fibres with low variability in diameter were selected and were individually attached to a tensile jig (paper template with a fixed gauge length of $20 \mathrm{~mm}$ ). Initially, the hair fibres in the tensile jigs were placed in an excicator for $24 \mathrm{~h}$ to avoid excessive humidity. Before the tensile test, the paper template was cut across so the measurements could be performed in the middle section of the hair fibre. The stretching measurements were performed at a rate of $1.5 \mathrm{~mm} / \mathrm{min}$, with a $0.01 \mathrm{~N}$ preloaded force, until the fibre broke [6]. The data are presented as a mean \pm SD of thirty samples.

\subsection{Statistical analysis}

Statistical comparisons were performed by one-way ANOVA with GraphPad Prism 5.0 software (La Jolla, CA, USA). Tukey's post hoc test was used to compare all the results between them. A p-value $\leq 0.05$ was considered to be statistically significant.

\section{Results and discussion}

\subsection{Effect of hair fragment size and mechanical wear time}

The methodology to evaluate the resistance of hair to mechanical wear was optimized regarding the hair fragments size and the time of mechanical insult (friction between the hair and the hardened steel balls during a vibrational vortex cycle). The effect of hairs' fragment size on the resistance to wear was evaluated by exposing $10 \mathrm{mg}$ of virgin and overbleached Caucasian hair fragments, with $0.25,0.5$ and $1 \mathrm{~cm}$, to the mechanical wear test conditions (2500 rpm vortex, $700 \mu \mathrm{l}$ water, 5 hardened steel balls, $3 \mathrm{~h}$ ). After the mechanical insult, the effect of the hair size and treatment (overbleaching) on hair fragments' integrity was visually analysed - Fig. 2 .

After the mechanical insult the samples of virgin and overbleached hair with $0.25 \mathrm{~cm}$ were very degraded, presenting few visible hair fragments. For the 0.5 and $1 \mathrm{~cm}$ fragments, there were some hair fragments visible at the end of the insult. It is noteworthy the presence of melanin in the mixture of the virgin hair samples, denoted by the brownish colour of the reaction mixture, which was more intense for the $0.25 \mathrm{~cm}$ fragments indicating a higher degradation degree for these samples. Analysing the results of the resistance to wear present in

Table 1

Effect of hairs' fragment size on the resistance to wear at the end of $3 \mathrm{~h}$ of mechanical wear test. Values represent the mean \pm SD of 2 independent experiments.

\begin{tabular}{lll}
\hline Fragment size $(\mathrm{cm})$ & Caucasian virgin hair (\%) & Caucasian overbleached hair $(\%)$ \\
\hline 0.25 & $73.35 \pm 3.61$ & $72.80 \pm 4.91$ \\
0.5 & $85.98 \pm 1.26$ & $80.79 \pm 2.35$ \\
1 & $84.99 \pm 1.55$ & $81.56 \pm 1.61$ \\
\hline
\end{tabular}


Table 1, no significant differences were observed between the resistance to wear of the virgin and overbleached hair for the $0.25 \mathrm{~cm}$ fragment size, after $3 \mathrm{~h}$ of mechanical insult. For the other fragment sizes, the virgin hair presented more resistance to the frictional insult when comparing with the results obtained for the overbleached hair samples. Since significant differences on the resistance to wear between the virgin hair (higher initial structural integrity and lower hair mass loss) and the overbleached hair (lower initial structural integrity and higher hair mass loss) were observed for the 0.5 and $1 \mathrm{~cm}$ fragments, only these samples were considered for further studies.

These results support the use of the non-corrodible hardened steel balls to promote the degradation of the hair samples for the determination of the resistance of hair to mechanical wear. During vortex the hair fragments are deformed and degraded by the forces exerted by the continuous movement of the hardened steel balls, and the level of degradation is related with the initial integrity of the samples.

\subsection{Effect of time of mechanical insult}

To study the effect of the mechanical insult duration on the resistance of hair samples to mechanical wear, $10 \mathrm{mg}$ of virgin and overbleached hair fragments with 0.5 and $1 \mathrm{~cm}$ were subject to the vortex (2500 rpm with 5 hardened steel balls) for 1, 3, 6, 12, and $24 \mathrm{~h}$ (Fig. 3).

The results for the resistance to mechanical wear with the time of mechanical insult showed that independently of the size of the fragments and type of hair (virgin vs overbleach), no significant differences between the samples were observed for the first $6 \mathrm{~h}$ of insult. For these time points $(1,3$, and $6 \mathrm{~h})$, all the hair samples showed variability, with the presence of several hair fragments at the end of the mechanical insult, particularly for the virgin hair. However, at the end of $12 \mathrm{~h}$ of mechanical insult, significant differences were observed comparing the virgin and the overbleached hair, and the size of the fragments for the same type of hair. For this time of friction, the differences of resistance to mechanical wear between the virgin and the overbleached hair (virgin hair $1 \mathrm{~cm}$ vs overbleached hair $1 \mathrm{~cm}$, and virgin hair $0.5 \mathrm{~cm}$ vs overbleached hair $0.5 \mathrm{~cm}$ ) were $\sim 5 \%$ and $\sim 10 \%$, for the $1 \mathrm{~cm}$ and 0.5 $\mathrm{cm}$ fragment sizes, respectively. It was expected to observe a decrease of the resistance to mechanical wear with time, however after $12 \mathrm{~h}$ of mechanical insult, the percentage of resistance to wear did not significantly decrease, regardless of the type of hair sample and fragment size. Only for the overbleached $1 \mathrm{~cm}$ sample, a slight decrease (not significant) in the weight loss was measured. We believe that the plateau observed after $12 \mathrm{~h}$ of insult, is most likely related with the size of the hair particles formed during the mechanic insult. After this time there is a lower probability of the aleatory movement of the hardened steel balls during vortex to exert frictional forces on the hair particles due to the small size of these.

Considering the time of mechanical insult and the hair fragments size, the condition that reflects into a greater extent the differences in the integrity of the hair fibres on the resistance to mechanical wear was the $12 \mathrm{~h}$ of mechanical insult using hair fragments with $0.5 \mathrm{~cm}$. Despite, other pore sizes, during the filtration step, could be tested to study the resistance to mechanical wear of hair with differatiated integrity profiles, the results obtained for the virgin hair and the overbleached hair (Tabe 1 and Fig. 3), support the use of membranes with $5 \mu \mathrm{m}$ pore size.

\subsection{Effect of hair ethnicity and hair treatment on the resistance to mechanical wear}

A great diversity of types of hair can be found around the world with differences regarding shape, colour, length and thickness. Despite this great diversity, the hair is generally categorized into three main groups African, Asian or Caucasian [21,22]. Generally, Asian hair presents a straight form, African hair tends to be frizzy while the Caucasian hair can vary from straight to wavy or curly [23]. The shape of the hair can strongly influence the behaviour of the hair fibres, particularly their resistance to mechanical stress [3]. For example, the high curliness of the African hair together with the lowest resistance of its cortex to mechanical stress makes this type of hair more brittle and more sensitive to excessive handling, when compared to the other types of hair [23,24].

Haircare cosmetic industry has developed a wide range of products to modify hair characteristics including hair colour and shape. Bleaching, colouring and permanent treatments can use harsh chemicals which induce irreversible damage to the hair fibres. The repetitive or excessive use of these treatments results in several negative effects on the hair structure, like the lifting and cracking of the cuticles, exposing the hair cortex to further damage, and affecting the hair properties $[3,25,26]$.

We applied the new methodology to study the influence of different hair ethnicities (Caucasian brown hair, Caucasian blond hair, African hair, and Asian hair) and different hair treatments (virgin hair, overbleached hair, coloured hair, and permed hair or straightened hair), on the resistance to mechanical wear. Hair fragments with $0.5 \mathrm{~cm}$ of each condition (ethnicity and treatment) were subjected to the mechanical insult for $12 \mathrm{~h}$ and the resistance to mechanical wear was evaluated by measuring the amount of hair mass that remained at the top of the membranes after filtration and drying (Fig. 4).

Comparing the results of resistance to wear of the hair from the three

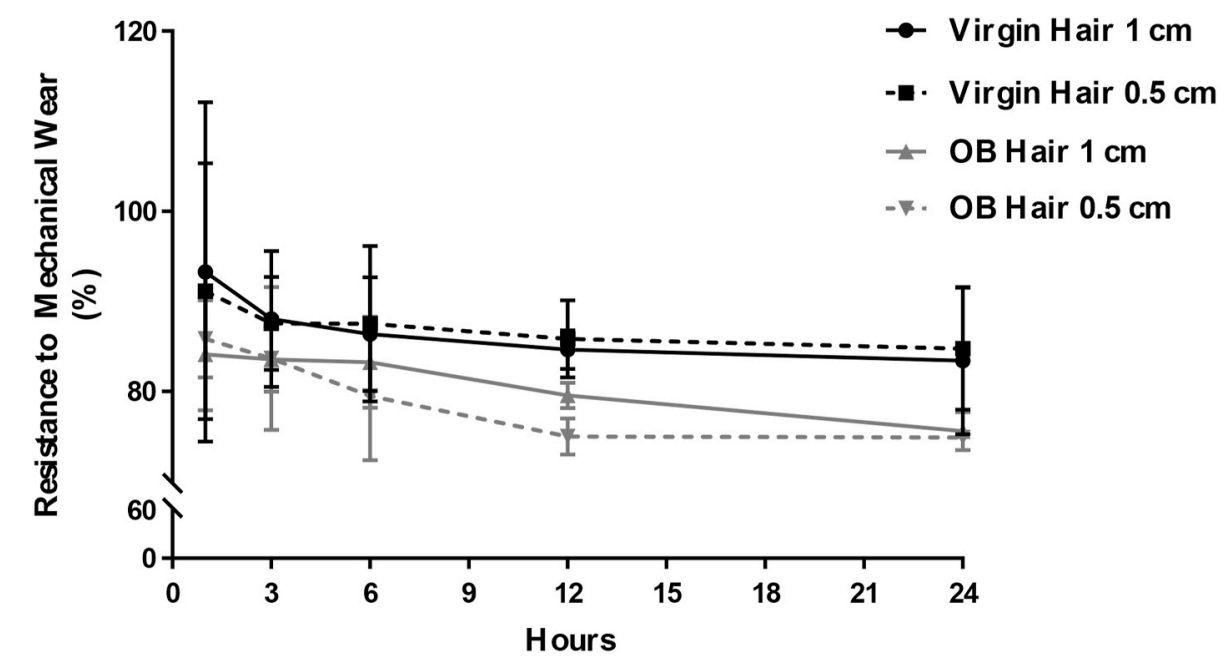

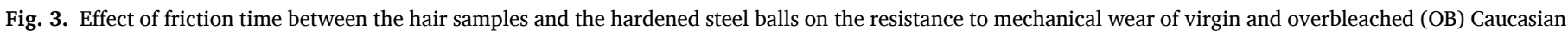
hair. Values represent the mean \pm SD of 3 independent experiments. 


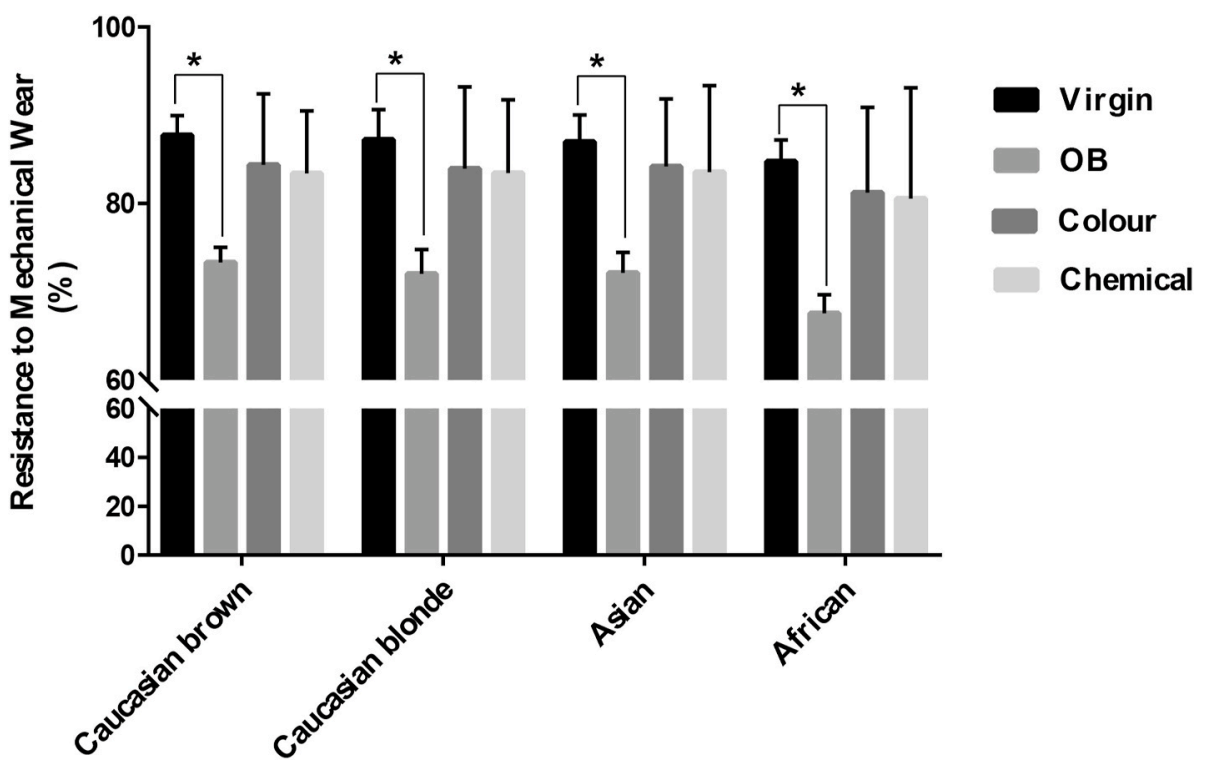

Fig. 4. Effect of hair ethnicity (Caucasian brown hair, Caucasian blond hair, Asian hair and African hair) and hair treatment (virgin hair, overbleached hair OB, coloration and chemical straightened/permed treatment) on the resistance to mechanical wear. The perming chemical treatment was applied on Caucasian and Asian hair and the straightening chemical treatment was used on the African hair. Values represent the mean \pm SD of 3 independent experiments. Statistically significant differences from the respective virgin hair are indicated as *p-value $\leq 0.05$. different ethnicities, the African hair presented the lowest resistance for all the tested conditions (virgin, overbleached, coloured, and chemical treatment), after the mechanical insult. A decrease in the resistance to mechanical wear around 3-5\% was measured for this type of hair when compared with the other ethnicities. This decrease is in accordance with the literature since curly hair tends to be more brittle than straight hair, present lower ability to stretch under mechanical stress, and thus are more prone to damage during the application of the frictional forces [27].

Regardless of the hair's ethnic background, the overbleached hair samples presented lower resistance to mechanical wear than the respective untreated virgin hair. These results confirmed the expected lower resistance of overbleached hair to the mechanical insult when compared with the performances of the virgin hair. Overbleaching is a process widely used in cosmetic applications, however, this procedure is extremely aggressive to the hair, inducing the damage and the weakening of the hair fibres [28]. The decrease in hair's properties as a consequence of overbleaching are mainly related to the damage of the hair cuticles, with the appearance of cracks and holes [29], and with the breakage of internal dissulphide bonds and the consequent formation of lanthionine bonds [28]. It is noteworthy that the overbleach treatment decreased the resistance of the hair fibres around $20 \%$ for the African hair when compared with the untreated virgin hair, while for the other types of hair the differences observed were less than $15 \%$. These results evidence the reduced mechanical properties and integrity of African hair and support is lower ability to resist to mechanical insults.

Hair cosmetic treatments, like coloration, straightening, or waving, can impart damage to the hair fibres, affecting their physicochemical properties. Hair coloration is based on the removal of the hair cortex melanin followed by the addition of a synthetic pigment. This process usually requires the application of strong oxidants with a negative impact on the quality of the hair fibres [30-32]. Permanent waving or straightening are among the most popular cosmetic procedures to change the shape of the hair. However, these procedures use chemicals and agents like strong alkaline agents, sodium or lithium hydroxide, thioglycolates or even formaldehyde. These chemicals besides damaging the hair fibres, decreasing the fibres' mechanical properties, are a hazard for users and for the environment [33-35].

The resistance to mechanical wear of coloured hair and hair subject to waving or straightening was also evaluated and compared with the respective untreated virgin hair. While for the overbleached hair there was a significant decrease in the resistance to mechanical wear around $15-20 \%$, for these treatments the decrease in the resistance, however not significant, was approximately $5 \%$. These results evidence that the procedures used to change the colour (without the overbleaching step) and the hair shape, are less aggressive to the structure of the hair fibres, resulting in higher resistance to the mechanical wear than the observed for the overbleached hair. Moreover, the differences observed between the overbleached hair and the coloured and the permed/straightened hair are most likely related to the effect of the treatment on the overall properties of the hair fiber rather than a possible mechanism underlying the resistance to mechanical wear. While the overbleached hair samples were prepared using four bleaching cycles and harsh chemicals, the coloured hair and the hair subject to waving or straightening were obtained after one cycle of treatment, using chemicals that do not compromise the structure and properties of hair to a greater extent like for the overbleaching process. Nevertheless, it is expected that the repeated application of the colouring and waving or straightening treatments will result in lower resistance of the hair fibres to the mechanical insult like the observed for the overbleached hair.

Hair fibres are complex structures composed of three different main regions: the cuticle, the cortex and the medulla. While the cuticle represents the outer layer of the fibre and is composed by overlapping flat cuticle cells, the cortex consists of a series of size decreasing components, including cortical cells, macrofibrils, microfibrils and protofibrils $[36,37]$. The effect of the mechanical insult on the hair structure was evaluated and the results were compared with the resistance to mechanical wear determined for each type of hair and treatment. Asian hair samples present at the top of the membranes $(5 \mu \mathrm{m}$ pore size) after filtration were analysed by SEM (Fig. 5). Despite the mechanical insult strongly affected the structure of all hair samples, the process was differentiated according to the type of treatment. For all the conditions (virgin, overbleached, colour treatment and chemical straighten/permed treatment) the mechanical insult induced the formation of spindle-shaped microkeratin structures or keratin powder-like material $[38,39]$. The microkeratin structures seem to be more conserved for the virgin hair followed by the coloured hair. For the hair exposed to the chemical treatment during hair straightening or waving, it is possible to observe the deposition of powder on the top of the microkeratin structures. This keratin powder-like material was even more evident for the overbleached hairs. Considering the level of integrity observed in Fig. 5, hairs with less initial damage result in more intact microkeratin structures while hairs with higher initial damage results in more powder-like keratin material. These differences observed on the type of structures formed after the mechanical insult are correlated with the resistance to mechanical wear results (Fig. 4). Virgin hairs have the highest resistance 

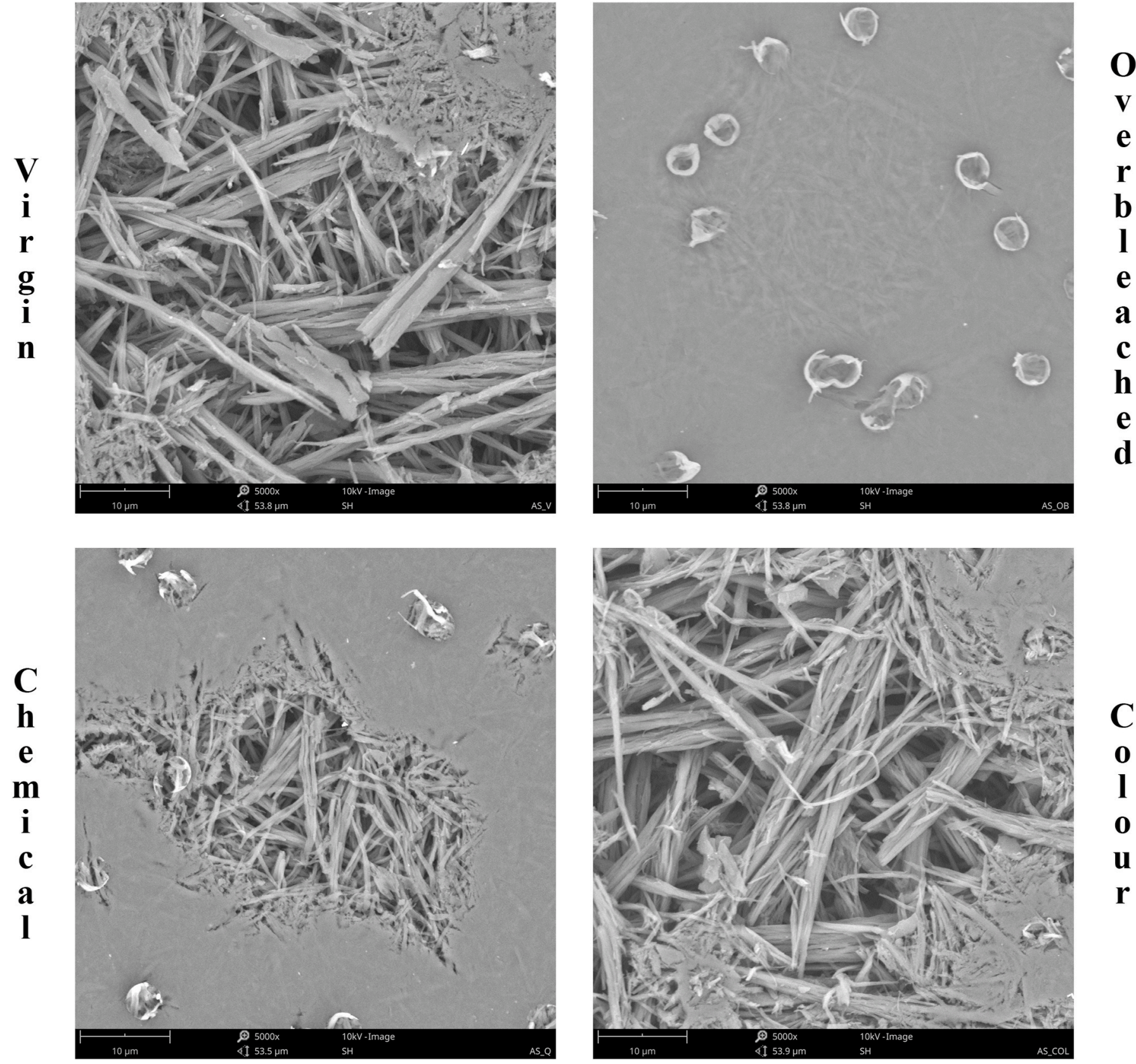

Fig. 5. SEM micrographs (5000x) of untreated virgin Asian hair (up left), overbleached Asian hair (upright), chemical straightened Asian hair (down left) and coloured Asian hair (down right), after application of frictional forces between the hair and the hardened steel balls for $12 \mathrm{~h}$ in the vortex.

to the mechanical wear (lowest mass loss) and the most intact keratin structures. While the overbleached hairs present the lowest resistance to the mechanical wear (highest mass loss) and the less intact keratin structures. Combining both results, resistance to mechanical wear and keratin structures formed, it is possible to organize the hair samples in terms of resistance to the mechanical wear from the highest to the lowest: Virgin Hair > Coloured Hair > Chemical straighten/permed Hair $>$ Overbleached Hair. The same tendency was observed for the hair samples of the other ethnic groups (Caucasian and African). However, it is noteworthy that for the African hair samples, a higher deposition of the powder-like keratin material was observed for all the treatments when comparing with the Asian and Causian hair samples (data not shown). This higher deposition of the powder-like keratin material is most likely related to the lower resistance to mechanical wear of the African hair as a consequence of its lower ability to stretch under mechanical stress, resulting in higher damage during the application of the frictional forces [27].

\subsection{Comparative protective effect of cosmetic formulations - methodology validation}

The methodology here developed to measure the resistance to mechanical wear was applied to assess the protective effect of a proteinbased hair cosmetic formulation. Due to their ability to bind to the horny layer of the skin and to its annexes, proteins have been explored for the development of formulations for topical application [13,40]. Moreover, proteins can be used to impart gloss, softness, conditioning and manageability to the hair and to prevent the damage to the hair fibers, due to their substantivity, amphoteric and buffering properties $[13,41]$.

Caucasian virgin hair meshes were treated with two fusion proteins based on the sequences of human eye $\gamma \mathrm{D}$-crystallin (Cryst) and a keratin- 
based peptide (KP) [3,13]. The KP-Cryst Wt and KP-Cryst Mut proteins were previously described to protect hair from thermal damage and showed great potential to be used in the development of cosmetic products for hair styling procedures based on high temperatures [19].

After protein application on the Caucasian brown hair, the resistance to mechanical wear (Fig. $6 \mathrm{~A}$ ) and the mechanical properties (Fig. $6 \mathrm{~B}$ ) of the treated and untreated hair were characterized. Analysing Fig. 6 A, it is possible to observe a protective effect conferred by both proteins, KPCryst Wt and KP-Cryst Mut, to the hair fibres, demonstrated by the higher values of resistance to mechanical wear comparing to the control (untreated virgin hair), after the mechanical insult. Although not significant, it was also observed an effect of formulation $\mathrm{pH}$ on the resistance to mechanical wear results: higher resistance values were obtained when the proteins were dissolved in the formulation at pH5. This behaviour could be justified by the distinctive location of the two proteins on the hair fibre with the formulation $\mathrm{pH}$ [19]. When both proteins were dissolved into the formulation with $\mathrm{pH} 5$, the proteins preferentially bound into the hair surface/cuticle; however, when the proteins were dissolved in a formulation with $\mathrm{pH} 9$, the proteins tend to penetrate more into the cortex. The increased protein concentration at the fibres' surface observed at $\mathrm{pH} 5$ could protect the fibres against the mechanical wear caused by the hardened steel balls, increasing the resistance results. Also, comparing the results for the 'Control pH5' and 'Control pH9' it was observed that the higher $\mathrm{pH}$ decreased slightly the resistance to mechanical wear, possibly due to the hair swelling and cuticle lifting [19] that could increase the hairs' fragility.

Relatively to the effect of the fusion proteins on the improvement in fibres' mechanical properties (Fig. 6 B), it was verified an increase in Young's modulus around $27-35 \%$ for the hair samples treated with the proteins. This increase could be related to the Greek key motifs structure of the KP-Cryst fusion proteins, known to be able to form a thin film around structures, decreasing the elasticity of the fibres and, consequently, increasing the Young's modulus values [42]. In this test, better results were obtained for the proteins dissolved in the formulation prepared at $\mathrm{pH} 9$. As explained previously, higher $\mathrm{pH}$ values are able to promote the hair swelling and the raising of the cuticles, facilitating the protein penetration into the cortex and allowing its interaction with the keratin filaments, increasing the fibres stiffness and Young's modulus results [19].

After the determination of the resistance to mechanical wear and Young's modulus values, for the different hair samples, the obtained data were normalized relative to the 'Untreated Virgin' sample. The 'Untreated Virgin' sample correspond to $100 \%$ while the 'Overbleached' corresponds to $0 \%$ of resistance to mechanical wear or mechanical properties. For this, the differences between the hair samples and the
'Overbleached' sample were calculated; then, the values of the differences were normalized relatively to the value obtained for the 'Untreated Virgin' sample. With this normalization, values higher than $100 \%$ will correspond to an improvement in the fibers' resistance to mechanical wear or Young's modulus relatively to the 'Untreated Virgin' control.

The ratio between the normalized percentages for the resistance to mechanical wear and Young's modulus (Resistance to mechanical wear/ Young's modulus), was determined and is represented in Fig. 7. This ratio gives information regarding the correlation between the results obtained for the resistance to mechanical wear and mechanical properties. Values equal to one represent the optimal correlation between the two measured parameters. For values higher than one there is a higher resistance to mechanical wear, on percentage, comparing to the improvement of the mechanical properties measured in Young's modulus. For values lower than one, the improvement of the hairs' mechanical properties on percentage is higher than the hairs' resistance

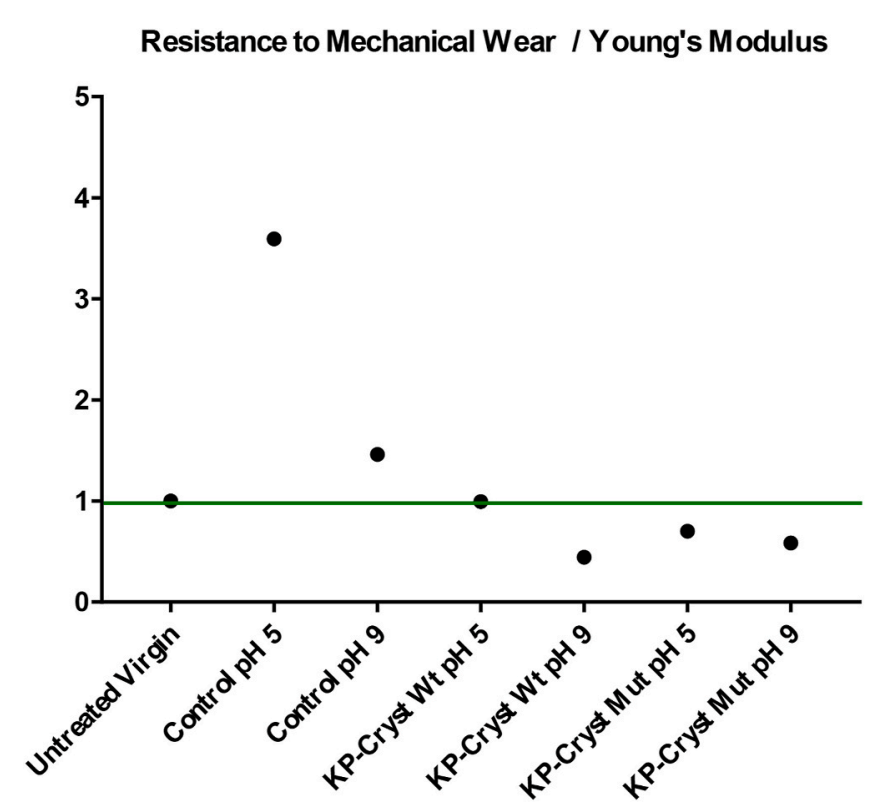

Fig. 7. Correlation between the Caucasian brown hair's resistance to mechanical wear and the calculated Young's modulus. (For interpretation of the references to colour in this figure legend, the reader is referred to the Web version of this article.)
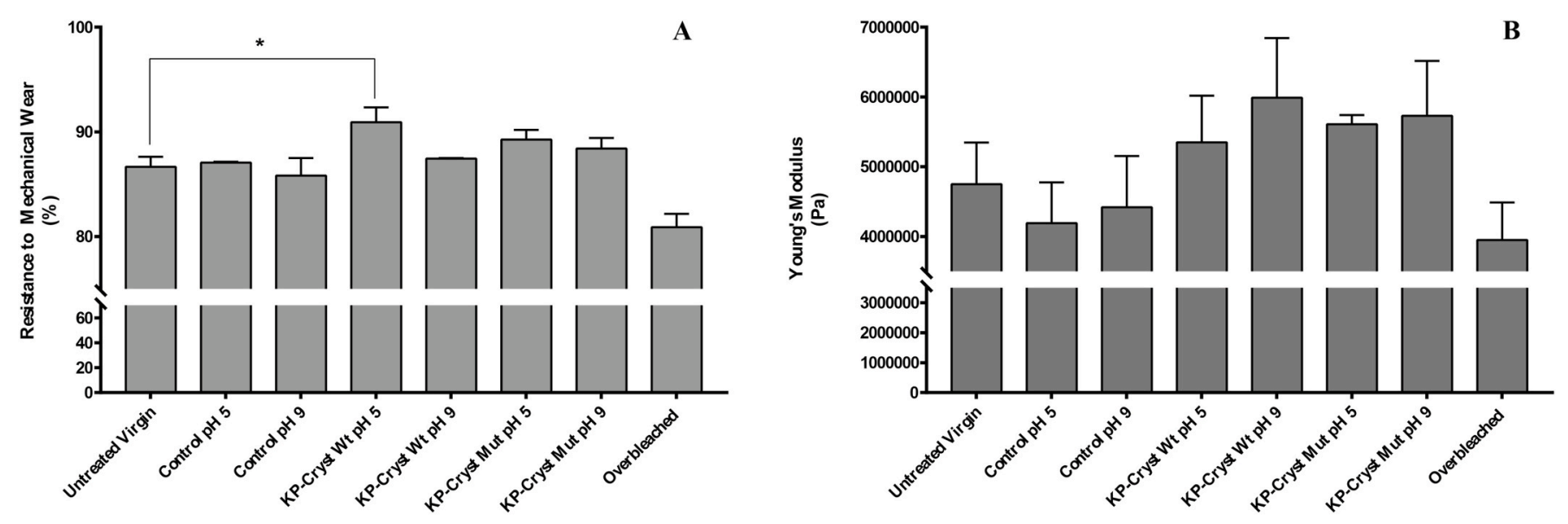

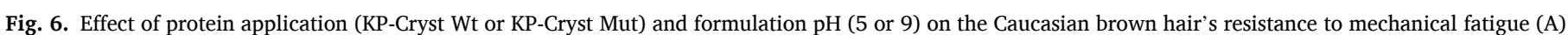

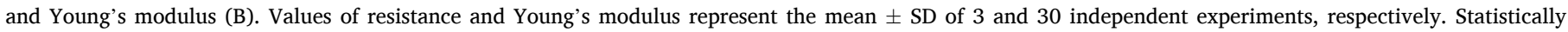
significant differences from the virgin hair are indicated as * $\mathrm{p}$-value $\leq 0.05$. 
to mechanical wear.

Due to the normalization of the values, the 'Untreated Virgin' hair sample present the best correlation between the two results. When the hair samples were treated with the KP-Cryst Wt protein prepared at $\mathrm{pH}$ 5 , a great correlation between the two parameters was also verified (Resistance to mechanical wear/Young's modulus $\sim 1$ ). For the other samples, there is a greater contribution of the proteins on the improvement on Young's modulus comparing to their contribution to the resistance to mechanical wear (Resistance to mechanical wear/ Young's modulus $<1$ ). The high value observed for the 'Control pH5' sample was obtained because this sample present the lowest value measured for Young's modulus (Fig. 6 B) and a resistance to mechanical wear value close to the value of the reference 'Untreated Virgin' sample.

The great correlation observed for the hair resistance to mechanical wear and the hair mechanical properties, support the use of the new methodology to evaluate the effect of cosmetic treatments and cosmetic products on the properties of hair from different ethnic backgrounds. It is important to note that the resistance to mechanical wear and the classical tensile traction methods give complementary information, and both can be used for the evaluation of hair properties. However, the resistance to mechanical wear has the advantage of being a less timeconsuming methodology, with a lower demand of multiple measurements.

\section{Conclusions}

In this study, we developed a new methodology based on the resistance to mechanical wear to evaluate the hair fibres integrity. The process was optimized considering the number of hardened steel balls, the fragments size of the hair fibres and the time of vortex agitation (friction between the hair and the hardened steel balls). The condition that promoted greater differences in the degradation profiles was the hair fragments with $0.5 \mathrm{~cm}$ exposed to $12 \mathrm{~h}$ of mechanical insult, using five hardened steel balls. After optimization, the resistance to mechanical wear was evaluated in Caucasian, Asian and African hair with different treatments (virgin, overbleaching, coloration and chemical straightening/perming). Regardless of the type of treatment, Caucasian and Asian hair presented higher resistance to mechanical wear than the African hair. In addition, the virgin hairs (no treatment) presented higher resistance than the coloured or the chemical straightened/ permed hairs, while the overbleached hairs presented the lowest resistance to mechanical wear indicating a high degree of damage of the fibres for this treatment.

In contrast to the current methodologies, this protocol avoids timeconsuming and multiple measurements which allow streamlining the process of cosmetic formulations evaluation over the hair fibre. The predicted damage rates based on hair mechanical wear resistance through the use of cosmetic formulations containing proteins exhibited protective effect, and hence correlated greatly to Young's modulus values for those treated hair fibres.

\section{Declaration of competing interest}

The authors declare that they have no known competing financial interests or personal relationships that could have appeared to influence the work reported in this paper.

\section{Acknowledgements}

This study was supported by the Portuguese Foundation for Science and Technology (FCT) under the scope of the strategic funding of UIDB/ 04469/2020 unit and BioTecNorte operation (NORTE-01-0145-FEDER000004) funded by the European Regional Development Fund under the scope of Norte 2020 - Programa Operacional Regional do Norte. AT thanks FTC for funding the scholarship with the reference SFRH/BD/ $114035 / 2015$.

\section{Appendix A. Supplementary data}

Supplementary data to this article can be found online at https://doi. org/10.1016/j.wear.2021.203612.

\section{References}

[1] R.A. Boulos, E. Eroglu, X. Chen, A. Scaffidi, B.R. Edwards, J. Toster, et al., Unravelling the structure and function of human hair, Green Chem. 15 (2013) 1268-1273.

[2] A. Tinoco, E. Antunes, M. Martins, F. Gonçalves, A.C. Gomes, C. Silva, et al., Fusion proteins with chromogenic and keratin binding modules, Sci. Rep. 9 (2019).

[3] C.F. Cruz, M. Martins, J. Egipto, H. Osório, A. Ribeiro, A. Cavaco-Paulo, Changing the shape of hair with keratin peptides, RSC Adv. 7 (2017) 51581-51592.

[4] C.F. Cruz, A. Ribeiro, M. Martins, A. Cavaco-Paulo, Effect of a peptide in cosmetic formulations for hair volume control, Int. J. Cosmet. Sci. 39 (2017) 600-609.

[5] M.F.R.G. Dias, Hair cosmetics: an overview, Int. J. Trichol. 7 (2015) 2.

[6] A. Tinoco, J. Gonçalves, C. Silva, A. Loureiro, A.C. Gomes, A. Cavaco-Paulo, et al., Keratin-based particles for protection and restoration of hair properties, Int. J. Cosmet. Sci. 40 (2018) 408-419.

[7] E. Berardesca, J.-L. Leveque, H.I. Maibach, Ethnic Skin and Hair, Informa Healthcare, New York, 2007.

[8] A. McMichael, Hair and scalp disorders in ethnic populations, Dermatol. Clin. 21 (2003) 629-644.

[9] S. Medland, D. Nyholt, B. McEvoy, A. McRae, G. Zhu, M. Ferreira, et al., Common variants in the trichohyalin gene are associated with straight hair in Europeans, Am. J. Hum. Genet. 85 (2009) 750-755.

[10] A. Franbourg, P. Hallegot, F. Baltenneck, C. Toutain, F. Leroy, Current research on ethnic hair, J. Am. Acad. Dermatol. 48 (2003) S115-S119.

[11] K. Song, H. Xu, K. Xie, Y. Yang, Effects of chemical structures of polycarboxylic acids on molecular and performance manipulation of hair keratin, RSC Adv. 6 (2016) 58594-58603.

[12] E. Fernández, B. Martínez-Teipel, R. Armengol, C. Barba, L. Coderch, Efficacy of antioxidants in human hair, J. Photochem. Photobiol. B Biol. 117 (2012) 146-156.

[13] A. Ribeiro, T. Matamá, C.F. Cruz, A.C. Gomes, A.M. Cavaco-Paulo, Potential of human $\gamma \mathrm{D}$-crystallin for hair damage repair: insights into the mechanical properties and biocompatibility, Int. J. Cosmet. Sci. 35 (2013) 458-466.

[14] Hans-Dietrich Weigmann, Sigrid B. Ruetsch, Mechanism of tensile stress release in the keratin fiber cuticle: I, J. Soc. Cosmet. Chem. 47 (1996) 13-26.

[15] M. Velasco, T. Balogh, E. Junko, W. Kagiyama, M. Dario, M. Robson, et al., Influence of Brazilian vegetable oils on mechanical resistence of hair fiber, Journal Biomedical and Biopharmaceutical Research (BBR) 1 (2015) 99-106.

[16] M.V.R. Velasco, TCdS. Dias, AZd Freitas, N.D.V. Júnior, CASdO. Pinto, T. M. Kaneko, et al., Hair fiber characteristics and methods to evaluate hair physical and mechanical properties, Brazilian Journal of Pharmaceutical Sciences 45 (2009) $153-162$.

[17] K.P. Evans Ta, A statistical analysis of hair breakage. II. Repeated grooming experiments, Cosmet Sci 6 (2010) 439-455.

[18] C. Baque, J. Zhou, W. Gu, C. Collaudin, S. Kravtchenko, J. Kempf, et al., Relationships between hair growth rate and morphological parameters of human straight hair: a same law above ethnical origins? Int. J. Cosmet. Sci. 34 (2011) $111-116$.

[19] A. Tinoco, J. Gonçalves, C. Silva, A. Cavaco-Paulo, A. Ribeiro, Crystallin fusion proteins improve the thermal properties of hair, Frontiers in Bioengineering and Biotechnology 7 (2019).

[20] S.F. Betz, Disulfide bonds and the stability of globular proteins, Protein Sci. 2 (1993) 1551-1558.

[21] G. Loussouarn, A.-L. Garcel, I. Lozano, C. Collaudin, C. Porter, S. Panhard, et al., Worldwide diversity of hair curliness: a new method of assessment, Int. J. Dermatol. 46 (2007) 2-6.

[22] L.J. Wolfram, Human hair: a unique physicochemical composite, J. Am. Acad. Dermatol. 48 (2003) S106-S114.

[23] A.J. McMichael, Hair and scalp disorders in ethnic populations, Dermatol. Clin. 21 (2003) 629-644.

[24] G. Wei, B. Bhushan, P.M. Torgerson, Nanomechanical characterization of human hair using nanoindentation and SEM, Ultramicroscopy 105 (2005) 248-266.

[25] J.M. Dyer, F. Bell, H. Koehn, J.A. Vernon, C.D. Cornellison, S. Clerens, et al., Redox proteomic evaluation of bleaching and alkali damage in human hair, Int. J. Cosmet. Sci. 35 (2013) 555-561.

[26] Bhushan B. Introduction - human hair, skin, and hair care products. In: Springer, editor. Biophysics of Human Hair, Biological and Medical Physics, Biomedical Engineering. Verlag, Berlin Heidelberg2010. p. 1-19.

[27] I.P. Seshadri, B. Bhushan, Effect of ethnicity and treatments on in situ tensile response and morphological changes of human hair characterized by atomic force microscopy, Acta Mater. 56 (2008) 3585-3597.

[28] A.N. Syed, H. Ayoub, A. Kuhajda, Recent advances in treating excessively curly hair, Cosmet. Toilet. 113 (1998) 47-56.

[29] M. Fernandes, A. Cavaco-Paulo, Protein disulphide isomerase-mediated grafting of cysteine-containing peptides onto over-bleached hair, Biocatal. Biotransform. 30 (2012) 10-19.

[30] D. Rollison, K. Helzlsouer, S. Pinney, Personal hair dye use and cancer: a systematic literature review and evaluation of exposure assessment in studies published since 1992, J. Toxicol. Environ. Health B Crit. Rev. 9 (2006) 413-439. 
[31] A. Correa, A. Mohan, L. Jackson, H. Perry, K. Helzlsouer, Use of hair dyes, hematopoietic neoplasms, and lymphomas: a literature review. I. Leukemias and myelodysplastic syndromes, Canc. Invest. 18 (2000) 366-380.

[32] K.L. Hamacher, Hair care: an illustrated dermatology handbook, Int. J. Dermatol 45 (2006) 622.

[33] E.M. Sanad, F.M. El-Esawy, A.I. Mustafa, H.A. Agina, Structural changes of hair shaft after application of chemical hair straighteners: clinical and histopathological study, J. Cosmet. Dermatol. 18 (2019) 929-935.

[34] V.H. Shetty, N.J. Shetty, D.G. Nair, Chemical hair relaxers have adverse effects a myth or reality, Int. J. Trichol. 5 (2013) 26-28.

[35] A.J. McMichael, Hair breakage in normal and weathered hair: focus on the black patient, J. Invest. Dermatol. Symp. Proc. 12 (2007) 6-9.

[36] E. Antunes, C.F. Cruz, N.G. Azoia, A. Cavaco-Paulo, Insights on the mechanical behavior of keratin fibrils, Int. J. Biol. Macromol. 89 (2016) 477-483.
[37] E. Antunes, C. Cruz, N. Azoia, A. Cavaco-Paulo, The effects of solvent composition on the affinity of a peptide towards hair keratin: experimental and molecular dynamics data, RSC Adv. 5 (2015).

[38] J. Fan, W-d Yu, High yield preparation of keratin powder from wool fiber, Fibers Polym. 13 (2012) 1044-1049.

[39] V. Kulkarni, J. Bradbury, The chemical composition of wool. XII further studies on cortical cells and macrofibrils, Aust. J. Biol. Sci. 27 (1974) 383-396.

[40] C. Barba, M. Martí, A. Roddick-Lanzilotta, A. Manich, J. Carilla, J.L. Parra, et al., Effect of wool keratin proteins and peptides on hair water sorption kinetics, J. Therm. Anal. Calorim. 102 (2010) 43-48.

[41] D. Cauwet-Martin, C. Dubief, Cosmetic Compositions Containing a Lipid Ceramide Compound and a Peptide Having a Fatty Chain, and Their Uses. United States: L'oreal (Paris, FR), 2000.

[42] G. Wistow, B. Turnell, L. Summers, C. Slingsby, D. Moss, L. Miller, et al., X-ray analysis of the eye lens protein $\gamma$-II crystallin at $1.9 \AA$ resolution, J. Mol. Biol. 170 (1983) 175-202. 